\title{
ADAPTATION TO CLIMATE CHANGE ON BEHALF OF BULGARIAN TOURIST BUSINESS
}

\author{
M. Kerezieva* \\ Department of Economics of Natural Resources, University of National and World Economy, Sofia, \\ Bulgaria
}

\begin{abstract}
The observed climate changes worldwide require adaptive action. Adaptation is an adjustment of natural or social systems to respond to actual or expected climatic impacts or effects, mitigate damage and absorb opportunities. The presented study explores how 50 Bulgarian tourist companies experience the process of adaptation to changed weather conditions in the area where their business operates. They answered a total of 22 questions designed to study the presence of motivation, knowledge, skills and acces to resources within the company. The results show that although that manegement posseses high motivation for adaptation, real adaptive measures are rarely undertaken, which could harm the financial results of the business due to damages by changed weather conditions and lack of adaptation.
\end{abstract}

Key words: weather, impact, tourism

\section{INTRODUCTION}

Changes occurring in the environment, direct the public attention to the thorough study of the interaction between natural and socioeconomic systems. Observed trends of climate change highlight the need to develop scenarios for the future development of climate change and its expected impact on the economy.

In the context of Bulgaria, since recently there is an analysis of the vulnerability of sectors of the Bulgarian economy to climate change (1). The analysis answers the question of how climate change on the territory of Bulgaria influences at the moment and how it will affect the future of the various sectors of the Bulgarian economy. Still there is no answer to the question of what is the degree if preparedness for these influences on behalf of companies. It is therefore necessary to examine the adaptation readiness in the various economic sectors of the Bulgarian economy. In this report, we will focus on the needs and difficulties expereienced by tourist business in Bulgaria in the process of adaptation to climate change occuring on the territory of Bulgaria.

\section{LITERATURE REVIEW}

The term "adaptation" is first used in the field

\footnotetext{
*Correspondence to: $M$. Kerezieva,General $N$. Stoletov Street \#11, Entrance A, ap36, Sofia 1309, Bulgaria,E-mail: mayakerezieva@gmail.com
}

of evolutionary biology and is related to the development of genetic or behavioral characteristics that allow the organisms or systems to cope with changes in the environment in order to survive and reproduce (2). Adaptive process can affect both individual organisms and populations of a species or an entire ecosystem.

The term is widely used in connection with the social systems in the eighties of the 20th century. One of the researchers devoted to this topic is anthropologist and cultural ecologist Julian Steward, who used the term cultural adaptation to describe the adaptation of various regional communities to the environment. O'Brien and Holland determined the adaptation process as a process during which a group of people added to their cultural practices new improved methods of dealing with the environment (3) . According to Nelson, Edgar and Brown adaptation is the process of making decisions and taking action in order to meet the current and future changes. Individuals and society adapt to take advantage of new opportunities or to respond to adverse external change (4). On the collective level, decision-making and action has been assigned to different management structures and this requires concerted effort to develop the ability to adapt (adaptive capacity) of the structure and the transformation of this policy into action. Actions may be spontaneous or planned 
and can also be triggered by changes already occurring in the external environment or future changes, which are expected to occur.

The Fourth Report of the IPCC contains one of the most widely used definitions of adaptation and according to it adaptation is "adjustment of natural or social systems to respond to actual or expected climatic impacts or effects, mitigate damage and absorb opportunities"(5). The term "climate stimuli" is closely related to adaptation to climate change, since they are the main driver of the process. Climatic stimuli are events or processes which require adaptation. They answer the question of "Adaptation to what".

Generally, adaptation to three types of climatic stimuli is mentioned in scientific literature:

- Global climate change: Climate change refers to changes in average climate or a change in its variations observed for a long period of time.
They can be due to natural phenomena or anthropogenic impacts on the atmosphere or land;

- Climatic variations: (climate variability) refers to variations in these averages, which does not include single recurring climatic events. These include prolonged droughts, flooding events resulting from the impact of the current El Nino for example;

- Single extreme events or catastrophic weather such as floods, droughts or storms.

Adaptation involves a change in something (system business sector, community or region) due to something else (defined stress and stimulus associated with change) (6). The description of the adaptation process requires a description of who or what adapts; what prompted him to adaptation, what is the process and in what form is it. These elements are presented in Figure 1.

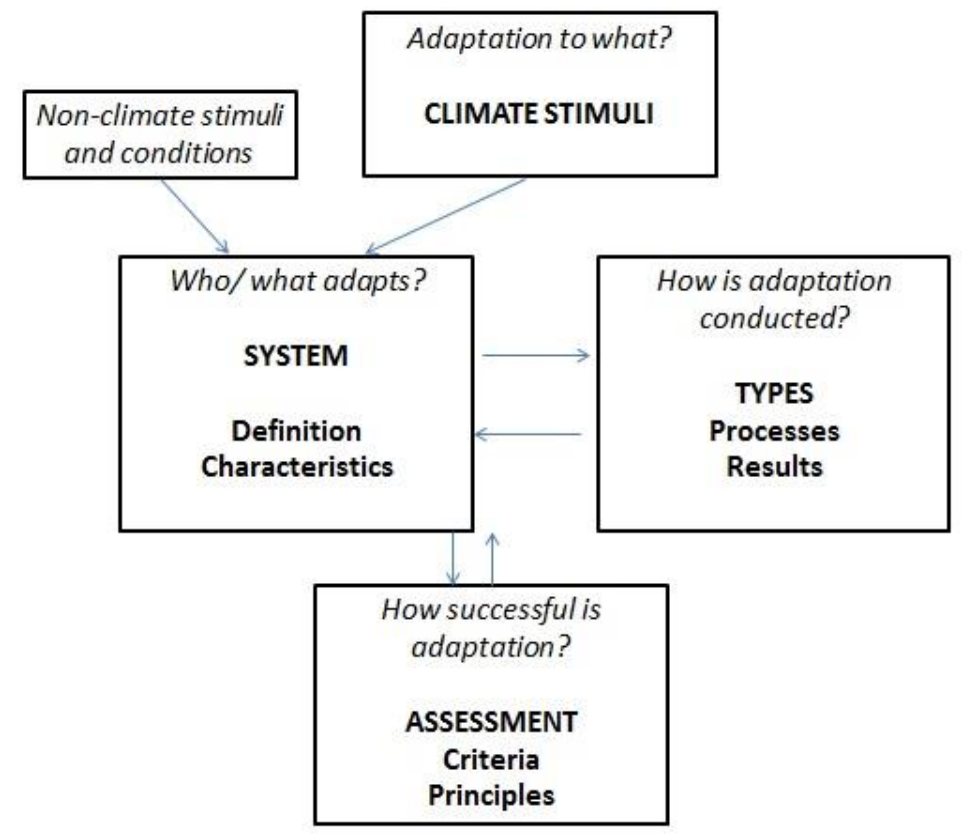

Figure 1. Adaptation process (9)

The main participant in the adaptation process is an individual or organism that adapts. Human systems can be motivated by private or public interest. Individuas, households and companies defend their private interests. Public interests are covered by various government institutions, national governments and intergovernmental organizations. Planned adaptation measures are considered a result of deliberate government policy and autonomous adaptation measures are taken by individuals or organizations.

Many authors use the term spontaneous adaptation as a synonym for autonomous adaptation by the author of this work does not agree, as there might occur misunderstandings. Autonomous adaptation may be spontaneous when decisions way of adaptation are taken intuitively and not based on the analysis and planning, where the decision to adaptation is based on a careful analysis and in-depth information. In the present report, the term "autonomous adaptation"is used for adaptation undertaken by a private agent, who can be a natural or legal person. Autonomous adaptation can be planned or spontaneous, reactive or proactive and will not be used as a synonym for spontaneous or reactive 
adaptation(7). On the other hand it is important clarification that autonomous adaptation can also be planned, but it is planned within their private or planned by an individual or household.

Factors for effective autonomous adaptation include the right motivation, knowledge, resources and skills of the private agents(8). With all these elements, is expected to realize the right actions to adapt the business to the changed climatic conditions.

\section{TASK}

The task of the research is to explore whether Bulgarian tourist companies posses the four factors for effective autonomous adaptation namely: right motivation, knowledge, resources and skills for adaptation, which are primordial for the success of adaptation to climate change in the area where their business operates.

\section{METHODS}

A survey was conducted among 50 Bulgarian tourist companies in the period 01/01/2015 $28 / 02 / 2015$. Representatives of the companies answered 22 questions designed to identify the impact of climate change on the hotel business and how the process of adaptation was conducted by these companies.

\section{RESULTS AND DISCUSSION}

The respondents were asked first to define the nature of their business (Figure 2). 34\% of them said their business was part of mountain recreational tourism, 32\% develop spa tourism, $20 \%$ develop rural tourism and $18 \%$ develop recreational sea tourism. The total sum of answers exceeds $100 \%$ because respondents were allowed to mark more than one valid answer.

\section{To which of the enumerated economic activities would you assign your business? \\ - TOURISM 1.1. recreational sea tourism \\ TOURISM 1.2. recreational mountain tourism

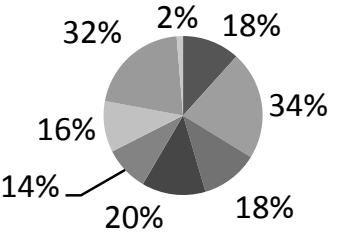 \\ - TOURISM 1.3. winter ski tourism \\ - TOURISM 1.4. rural tourism \\ $\square$ TOURISM 1.5. business tourism \\ $\square$ TOURISM 1.6. cultural tourism \\ - TOURISM 1.7. spa tourism \\ $\square$ TOURISM 1.8. other}

Figure 2. Question 1

Regardless of the type of tourism they develop, almost all respondents agree that on the territory of Bulgaria climatic changes are observed (Figure 3). The largest percentage of respondents claim that according to their observations these changes include milder winters $(78 \%)$, torrential rains and floods $(54 \%)$, a rare snowfall $(50 \%)$ and more summer days with a high temperatures in summer (42\%) (Figure4). Described weather phenomena coincide with the official information provided by the National Institute of Meteorology and Hydrology (NIMH) at BAS on facts proving climate change in Bulgaria.

\section{According to you are there climate changes on the territory of} Bulgaria during the last ten years?

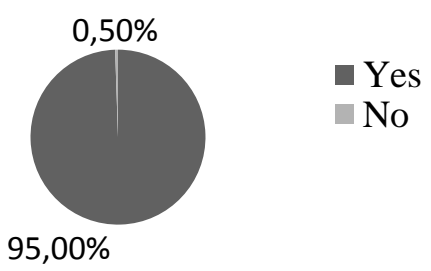

Figure 3. Question 2 
Please describe the climate changes observed by you.

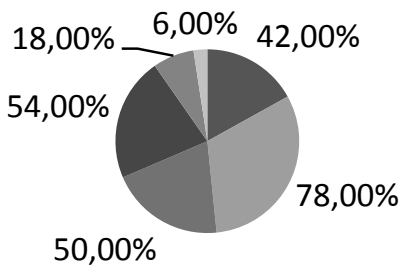

- More summer days with higher mean temperatures

Milder winters

- More rare snowfalls

- Floods and torrents

- Longer drought periods

Other

Figure 4. Question 3

Asked how the observed climate changes affect their business, $62 \%$ of companies responded that the influence is unfavorable; $18 \%$ consider there is no impact on their business; $16 \%$ of companies observe favorable impact and $4 \%$ believe that the impact is highly unfavorable (Figure 5). As noted in the course of the survey, the type of tourist activity is essential for the effect of climate change on that activity and the type of adaptation measures that respondents take. Hotels that rely primarily on congress and spa tourism are affected to a lesser degree by climate change, because their activities are conducted indoors and therefore are not dependent on external climatic conditions. In contrast, winter tourist sites located in the ski resorts are most negatively affected by the lack of regular snowfall and shorter duration of the winter season. For seaside resorts, the increased number of summer days helps to increase the duration of the summer season, but on the other hand extreme weather events, such as torrential rains and flooding in summer resorts, creates damages to infrastructure.

The effect of climate change requires action by the business so as to limit damages in cases where impacts are unfavourable or respectively to exploit new opportunities if the effect on business is favorable. 54\% of respondents say they have or intend to have launched measures to limit the damage from negative impact, $18 \%$ will benefit from new opportunities, while $28 \%$ do not think that any changes are needed (Figure 6).

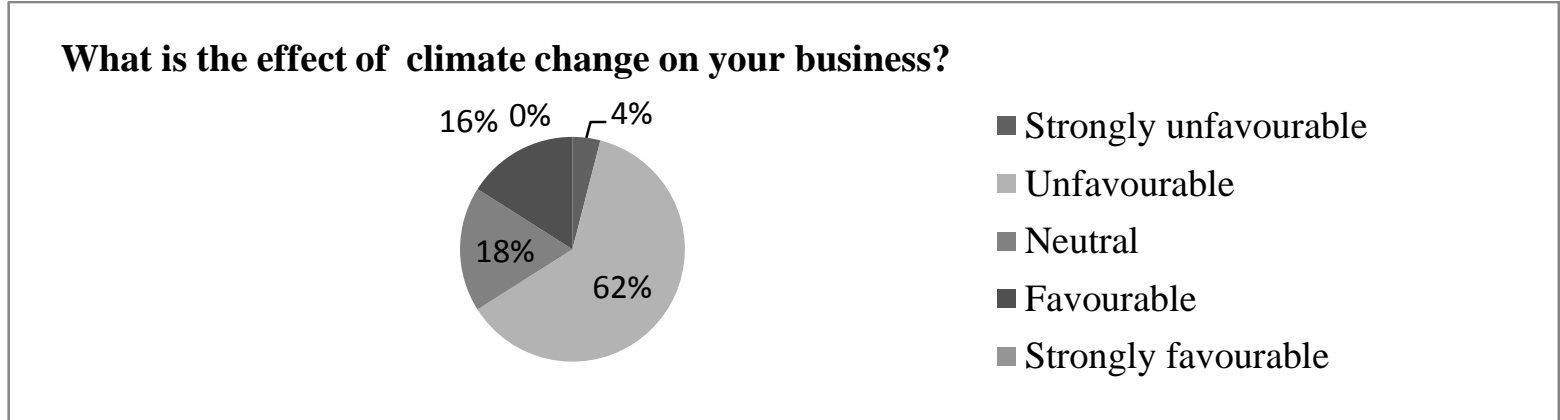

Figure 5. Question 4

Do you think that you should make changes in your activity in order to answer to changed climate?

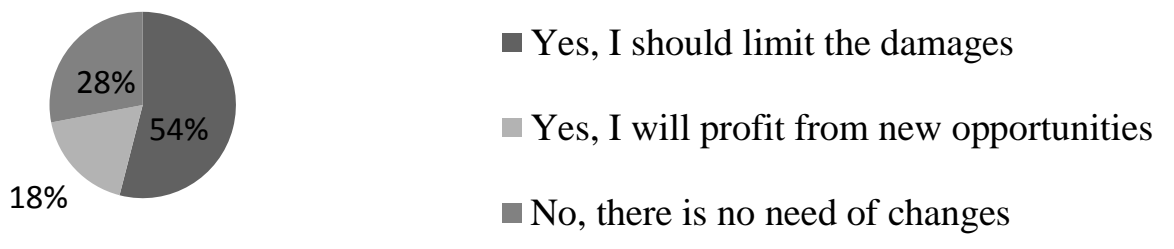

Figure 6. Question 5

Responses so far have confirmed that the majority of respondents are aware of the existence of climate change on the territory of Bulgaria, they can properly describe them and the largest share of these effects is unfavorable and therefore intend to take measures to limit the damage to their business. The first responses allow us to conclude that the observed hoteliers who are under study report high motivation for taking adaptation action to the effects of climate change. 
The next series of five questions aim to investigate the level of awareness on behalf of tourist companies (Figures 7-11). Through these questions, we examine whether respondents are familiar with the official position of the institutions in Bulgaria and the European Union concerning the existence of climate change, the future outlook for the climate in our country and the measures taken by the State and the European Union. A large percentage of respondents said they have heard about climate change, mentioned in the media (Figure 7), but the majority of them do not know what is the exact official forecast of NIMH (Figure 8). Although there is a formal assessment of the impact of climate change on the Bulgarian economy made by the Ministry of Environment and Water (MEW), most companies are not aware of this analysis (Figure 9). The majority of companies are not familiar with any recommendations for adaptation by the European Commission (Figure 10) and do not know what are the adaptation measures taken so far by the Bulgarian Government (Figure 11). Based on these answers, we can conclude that awareness among businesses on official data on climate change and the response of the state is particularly low. This lack of information may compromise adaptation actions by companies because management decisions in the process of adaptation to climate change will not be based on official data.

Have you heard the media mentioning climate changes?

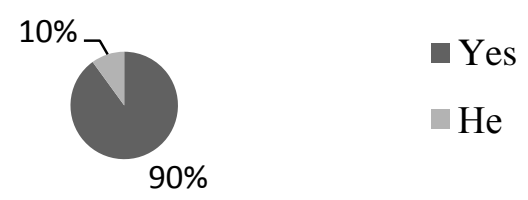

Figure 7. Question 6

Do you know what is the official forecast about climate changes, expected in Bulgaria until 2050?

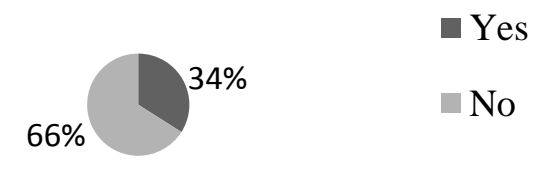

Figure 8. Question 7

Are you familiar with the effect of climate change to Bulgarian economy according to the official anlysis, provided by Ministry of Environment and Water Resources (MEW) ?

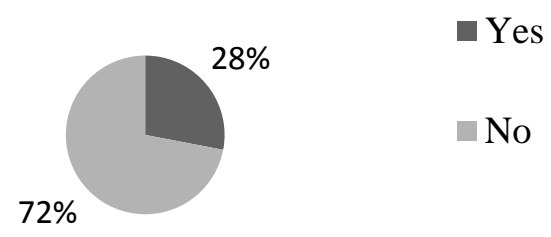

Figure 9. Question 8

Are you familiar with the recommendation for adaptation by the European Commission?

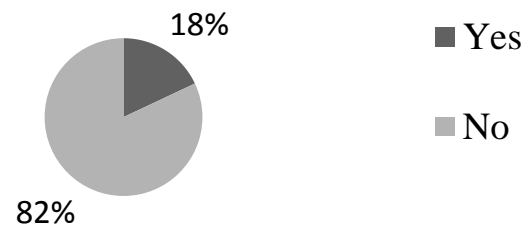

Figure 10. Question 9 
Are you familiar with the actions undertaken by the Bulgarian

institutions in order to assist the adaptation to climate change by

companies and households?

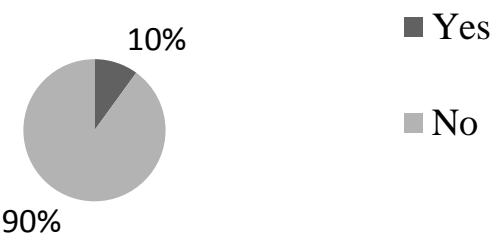

Figure 11. Question 10

Asked to give an opinion on the role of the state in the process of adaptation to climate change, $52 \%$ of respondents consider that measures by government are not suuficient to adapt existing infrastructure to changed climate conditions; $44 \%$ felt the need for more information about climate change and its impact; $10 \%$ considered it necessary to receive financial assistance in order to adapt their business more successfully to climate changes (Figure 12).

\section{Do you consider that the actions undertaken by the State are sufficient? \\ I am not familiar with the realized actions}

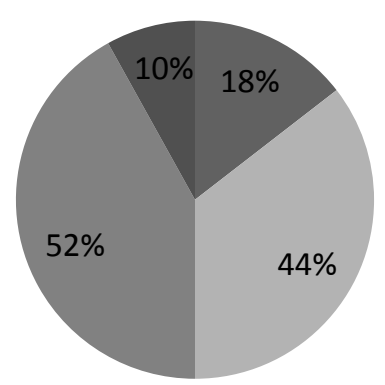

$\square$ No, we need more information about climate change and its impacts

$\square$ No, the State needs to do more about the adaptation of existing infrastrucure to changed climate conditions

- No, financial support is needed on behalf of private sector

Figure 12. Question 11

Next questions (Figures 13- 17) aim to explore adaptation skills manifested by companies, namely: what is the phase of the adaptation process which the company is experiencing, management decisions are based on which type of information, whether the measures taken already have a successful result or outcome is expected in the medium term. Although, as mentioned, the majority of companies declare that climate change has a negative impact on their business, $54 \%$ of them say that despite their intentions adaptation has not yet taken concrete dimension (Figure 13). Only 8\% of them have developed a specific plan for adaptation and other $8 \%$ have already taken action. These responses are worrying because they proove low reactivity on the negative impacts of climate change, which might lead to losses for the business of respondents.

When asked about the type of selected adaptation measures, $58 \%$ of companies responded that they intend to offer additional products or services, $20 \%$ plan to switch to offering a replacement service or product. This proves that in tourism sector, the most common adaptation measure is diversification of activities. This is particularly evident in winter ski resorts where in the absence of snow cover, hotels switch to offering complementary services, namely: congress and entertainment events.

Concerning the success of the measures taken, only $22 \%$ believe that measures have already produced results, while another $46 \%$ expect the result to occur in the medium term of 5 years (Figures 15 and 16).

Unfortunately, $34 \%$ of respondents say they base their choice on intuition (Figure 17). Indoor analysis about climate change impacts on business and adaptation measures is prepared by $60 \%$ of companies and $20 \%$ trust 
the practices used by other successful companies in the industry. Especially worrying is that none of the respondents used official information published by state institutions, which is expected to be the most professional and objective. Alhtough such kind of information is published by institutions it seems that its existence is not well known by private sector. It might be government's mistake that obviously it does not give enough publicity on its analysis. On the other hand the disinterest of the companies and their lack of confidence in the authorities might be considered as the second reason for this phenomenon.

Mark the answer which is valid for your business:

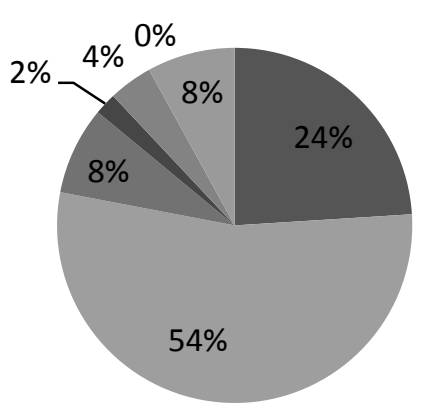

I do not intend to adapt my business

$\square$ I intend to adapt my business but I am not yet aware of the exact actions that need to be done I have prepared a detailed plan of the exact actions for adaptation

I have realized entirely the planned actions for adaptation of my business

I have started actions for adaptation but have not yet finished all that is planned

In the moment I monitor the result from the implemented actions

Figure 13. Question 12

Please descibe the adaptation measures that you have planned or implemented?

- Replacing a service/product with a new service/product

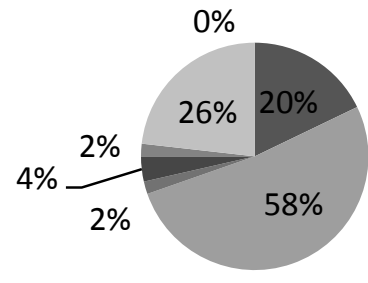

- Offering a new service/product

- Changing the time period of the offered service/product

- Changing the location of the offered service/product

- Others

Not applicable

Figure 14. Question 13

Do you consider the adaptation measures which are implemented as succesful?

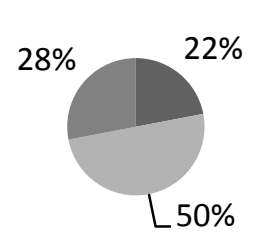

Yes

No

Not applicable

Figure 15. Question 14

Do you think that the result will be evident in the next 5 years?

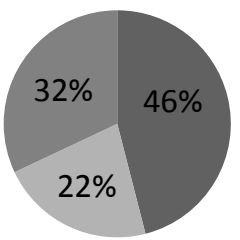

- Yes

No

Not applicable

Figure 16. Question 15 
On what do you base your management decisions about adaptation?

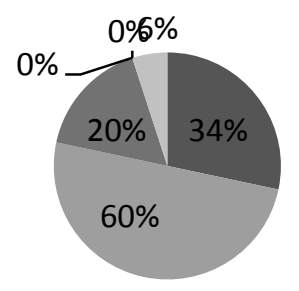

- Intuition

Indoor analysis

- Best practices by other companies

- Services of a consultancy firm

- Official data

Not applicable

Figure 17. Question 16

The last series of questions examined access to resources needed to implement adaptation measures. Since in some cases, transaction costs can be significant, access to financial sources was examined. The majority of respondents $(58 \%)$ said that the company does not have its own resources for investment in adaptation measures, and only $1 / 3$ of those polled said they have such resources (Figure
18). $66 \%$ are insured property of the company, so that it is protected against adverse climate events (Figure 20). Most companies (94\%) have not benefited from European programs to ensure the cost of adaptation of business (Figure 22) as the probable cause of $76 \%$ is that they did not know any programs that finance this type of expenditure (Figure 21).

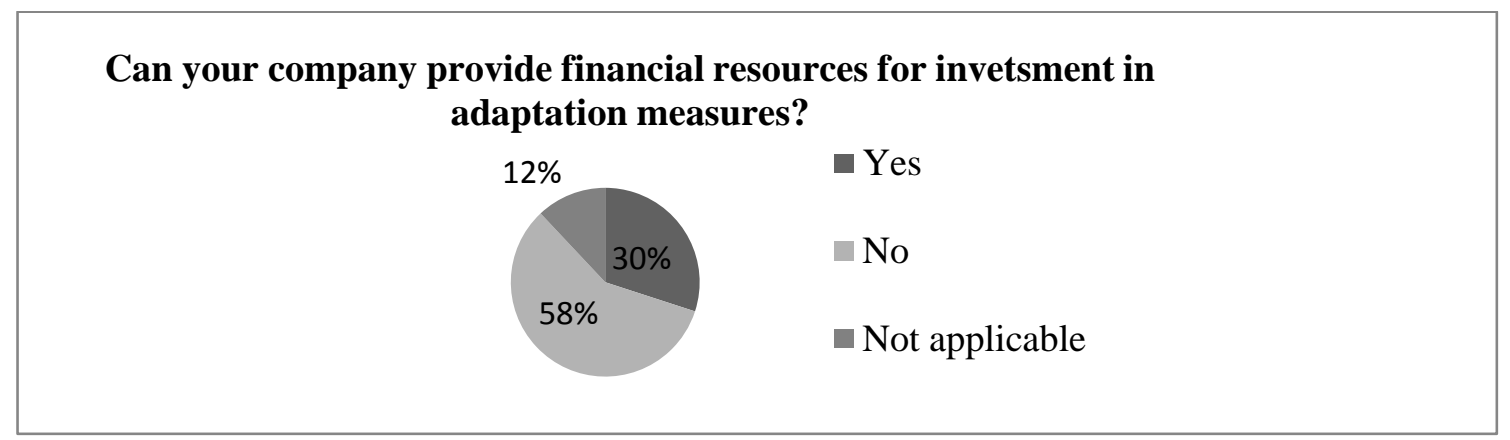

Figure 18. Question 17

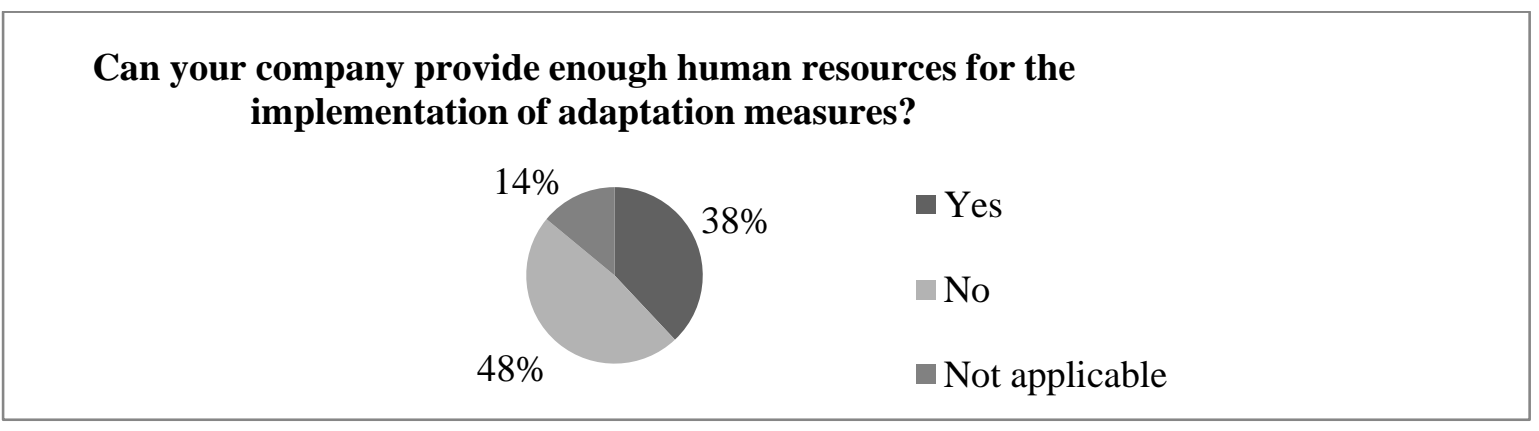

Figure 19. Question 18

Is your company insured against damages resulting from climate changes?

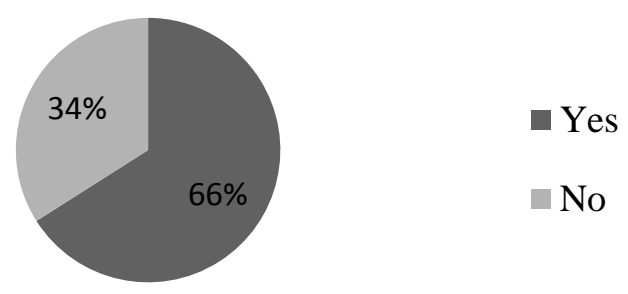

Figure 20. Question 19 
Are you familiar with European programs that could cover your expenses on adaptation actions?

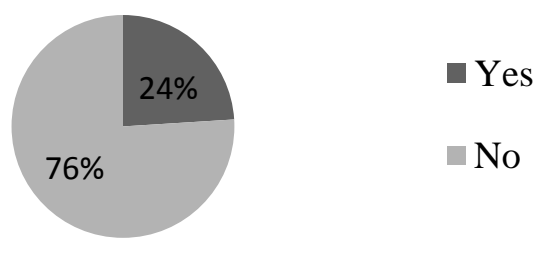

Figure 21. Question 20

On access to human resources, $48 \%$ of companies said they do not have the necessary staff for the implementation of selected adaptation measures, and $38 \%$ believe that there will be difficulties in this regard (Figure 19). Additional staff is needed in hotels mainly in offering additional tourist attractions in servicing mass events such as seminars, conferences, weddings and other events or extend the length of the active season. The problem is that in the summer resorts the busiest period is the same for all hotels and they all need staff at the same period of the year. Furthermore, special events organized in hotels require part-time employment of experienced staff, which is often difficult to provide and need to hire people with no experience.

\section{Have you ever received European funds to cover your expenses on adaptation actions?}

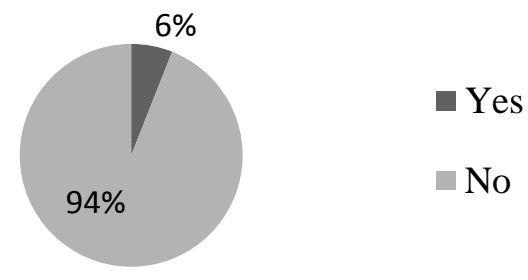

Figure 22. Question 21

Do you see any additional bariers to adaptaing your business to climate change?

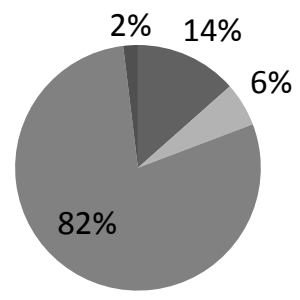

- Yes, in Bulgaria I can`t find the necessary raw material/ technologies

Yes, In my company there is lack of knowhow

No, there are no other bariers

Figure 23. Question 22

Asked whether they saw other barriers to successful adaptation to climate change, the majority of companies (82\%) say they do not see any obstacles. 14\% say that within the country they can not find the necessary raw materials and equipment, and $6 \%$ believe they lack the necessary know-how (Figure 23). The rest of the respondents indicated various obstacles, mostly related to administrative difficulties in reorganizing their activities.

\section{CONCLUSIONS}

Based on the answers provided by 50 tourist companies about the process of adaptation of their businesses to climate change, observed in Bulgaria, and exploring the four factors for adaptation success (motivation, knowledge, skills and access to financial, technological and human resources), it can certainly be concluded that motivation is the factor which is most strongly present. Companies 
demonstrate confidence in the manifestation of climate change on the territory of Bulgaria and declare that their business is strongly influenced by changes in climatic conditions. Despite this high motivation, however, there is a weak reactivity and most companies are in a phase of selection and definition of adaptation actions, and have not made any real steps for their implementation. This delayed reaction and lack of proactivity could harm the financial performance of companies and could lead to financial losses. Companies do not use available official information provided by state institutions on climate change and base their decisions mostly on intuition, indoor analysis and best practices from other companies. As these sources of information are not sufficiently reliable and objective, basing managerial decision on them might be misleading. Concerning access to financial, human and technological resources, it is positive that many companies have insured their property, but it is unfortunate that there is not enough information for European Union funds to ensure transaction costs on reorganizing the business activity in order to face the challenges due to the changing weather conditions.

\section{REFERENCES}

1. Ministry of Environment and Water Resources (MEW) , 2014, Analysis and risk assessment of vulnerability of sectors of Bulgarian economy, 2014 г, Available at :http://www.moew.government.bg/?show $=\mathrm{h}$ tml\&hid $=180$
2. Barry Smit, Johanna Wandel, Adaptation, adaptive capacity and vulnerability, Global Environmental Change 16 (2006), www.elsevier.com/locate/gloenvcha

3. O'Brien, M., Holland, T.D., 1992. The role of adaptation in archeological explanation. American Antiquity 57, 36-69

4. Nelson, Edgar, Brown, Adaptation to environmental change: contributions of a resilient network, Annual Review of Environment and Resources. 2007. 32:395419 , http://environ.annualreviews.org

5. IPCC, 2001, IPCC Third Assessment Report - Climate Change 2001, Available at:http://climateknowledge.org/figures/Wu Gblog_figures/RBRWuG0049_IPCC_Glos sary.pdf

6. Smit and Polifosova, 2001, Chapter 18 Adaptation to Climate Change in the Context of Sustainable Development and Equity, Third Assessment Report , 2001, http://www.grida.no/publications/other/ipcc _tar/?src=/climate/ipcc_tar/

7. IPCC, 2007, IPCC Fourth Assessment Report: Climate Change 2007, Cambridge University Press

8. Fankhauser, Samuel, Joel B. Smith, and Richard S.J. Tol. 1999. "Weathering climate change:some simple rules to guide adaptation decisions.” Ecological Economics 30 (1999)

9. Aleksiev, Aleksi, 2008, Adaptive capacity of grain production in Bulgaria, Economy and management of agricultire Journal 